the works of the Cargo Fleet Iron Co., Ltd. The whole of the plant at these works has been recently remodelled and fitted with the latest labour-saving devices and plant for recovery of by-products; the Talbot continuous steel process, which was introduced to the notice of English metallurgists only in 1900, has been adopted, and at the Cargo Fleet Works each of the three furnaces holds about I75 tons of molten steel.

On Tuesday, August 7 , the section began its proceedings with a paper by Prof. W. E. Dalby on experiments illustrating the balancing of engines. The beautiful working models which Prof. Dalby has designed to illustrate the principles which underlie the problem of balancing various types of engines were shown in operation, and, as the president remarked during the discussion, it was a pity that the London County Council had not made use of the author's services in this field of engineering research before it began the design of a large generating station not half a mile away from Greenwich Observatory.

$\mathrm{Mr}$. G. Stoney then read a paper on recent advances in steam turbines, land and marine. The figures given by the author showed how wonderful had been the advance since $\mathrm{Mr}$. C. A. Parsons built his first turbo-dynamo of about io h.p. in 1884 ; at the present time $6000 \mathrm{kw}$ generators are in course of construction, while turbines of $10,000 \mathrm{kw}$. are proposed for the great power scheme to supply electric energy in bulk for London. The use of large turbine blowing engines in metallurgical work has also rapidly developed during the past three or four years, while for marine purposes the total horse-power of turbines, either completed or on order, now approaches $\mathrm{I}, 000,000$. Mr. Stoney also described the "vacuum augmenter," a device for increasing the vacuum in the condenser without increasing unduly the volume of the circulating water by the use of a steam jet placed in a contracted pipe between the condenser and the air pump, which compresses the air and vapour from the condenser and delivers it to the air pump through a small auxiliary condenser.

The next paper was by Mr. J. Smith, on an application of stream-line apparatus to the determination of the direction and approximate magnitude of the principal stresses in certain portions of the structure of ships; this valuable paper was, the president stated, one of the first fruits of the laboratory of the Royal Naval College at Greenwich. The author showed that a strain diagram of the deck of a ship very closely approximated to the stream-line shown hy Prof. Hele-Shaw's well-known apparatus, in which a very thin film of water is compelled to flow between two sheets of glass.

In the afternoon the section had a joint meeting with the physical and educational sections, and a discussion on the teaching of mechanics was opened by a paper by Mr. C. E. Ashford, headmaster of the Roval Naval College, Dartmouth. In his paper Mr. Ashford pointed out that there was a serious danger that school science might become as academic as classics, and he directed attention to the absolute necessity of employing for laboratory experimental work, not toys, but apparatus such as screwjacks, Weston's blocks, \&c., and also to the great need of experiments for showing the phenomena of kinetics. several new pieces of apparatus designed for this purpose by the staff at the college were described and illustrated.

Wednesday, August 8, the last day of the meeting, was an unusually busy one for the section; no fewer than six papers were dealt with. Prof. Ashcroft described, and showed in operation, the Central Technical College lecture table testing machine, an exceedingly ingenious and beautiful piece of apparatus; Prof.. Ashcroft has adopted, with, however, considerable simplifications, the plan first devised by Prof. Kennedy, of using a "spring bar" to measure the loads upon the specimen under test, and to give one of the two necessary motions to the recording apparatus, thus overcoming the difficulties unavoidable when an attempt is made to keep the steelyard of the testing machine floating during the final drawing-down stage prior to fracture.

The next paper was one by Prof. J. B. Henderson, on recent advances in our knowledge of radiation phenomena and their bearing on the optical measurement of temperature. After discussing the four laws of radiation from an vo. I 924 , VOL. 74$]$ ideal black body, the author dealt with pyrometers based on these laws, such as Féry's, and the optical thermometer of Holborn and Kurlbaum.

Mr. S. Cowper Coles read a paper on electropositive coatings for the protection of iron and steel from corrosion, and showed a number of beautiful examples of electrodeposition. In the discussion Colonel Crompton stated that the processes invented by the author had solved a very difficult problem in connection with the piston rods of steam engines using very high-pressure steam, for it was now possible to give these rods a very hard, incorrodible surface without any sacrifice of strength.

In a paper on suction-gas plants, Prof. Dalby dealt with the principles underlying the design of such plants, and then described a number of plants which were entered for the recent trials in connection with the Royal Agricultural Society's show at Derby, and the methods of starting such plants. In reply to the discussion, Prof. Dalby stated that a $\mathrm{I}_{5}$ h.p. engine would use about $0.7 \mathrm{lb}$. anthracite coal per B.H.P. during running, or, if allowance is made for lighting up and standing by, about $\mathrm{I} \cdot \mathrm{O}$ lb. per B.H.P. hour.

Mr. W. A. Scoble, in a paper on the strength and behaviour of ductile materials under combined stress, described the results of a series of tests of steel bars with a distribution similar to that which occurs most frequently in practice, as obtained under combined bending and twisting; the experiments showed conclusively that the maximum principal stress and the maximum shear both varied through a wide range, the point used as a criterion of strength being the yield point.

The section concluded its business with the reading of a paper by Mr. D. Mackenzie, on waterproof roads as a solution of the dust problem. The various processes at present in use were described and their deficiencies pointed out. Tar alone was most unsatisfactory; at the end of twelve months it had entirely disappeared; the best material, he considered, was "tarmac," made from blastfurnace slag broken when hot and immediately immersed in hot tar; only forge pig slag should be used for this purpose.

It was a great pleasure to see the section so well attended; especially when it is remembered that the early days of the meeting clashed with the summer meeting of the Institution of Mechanical Engineers. No doubt much of the increased interest shown in the work of the section was due to the personal popularity of its distinguished president.

T. H. B.

\section{EDUCATION AT THE BRITISH ASSOCIATION}

$A$ MONG the "growing points" mentioned by Prof.

M. E. Sadler in his address were the keenness of intelligent workmen to make the elementary schools better, the demand by adult workers for an education touched by imagination, humanity, and civic idealism, the encouragement of education by employers of labour, educational experiments carefully planned and systematically watched (e.g. in practical courses of study and corporal training in higher elementary schools for ages twelve to fifteen, and in the actual results of postponing the beginning of Latin until twelve years of age), and the need for continuation schools to check the drift into the physical and intellectual disorder of the unemployed. A full report of Prof. Sadler's address appears in the School World for September.

The list of schools and other institutions to which visits had been arranged included the Yorkshire School for the Blind, the classes in domestic economy for employees at Messrs. Rowntree's Cocoa Works, the British Botanical Association, with its extensive arrangements for the supply of botanical material, and two hospitals for the insane, the latter typifying the help which the schools may expect to receive from all contributions to mental science.

Health at School and Physical Education are topics which seem amenable to scientific treatment, and as such were very properly placed in the forefront of the programme. Sir Edward Brabrook presented the report on the conditions of health essential to the carrying on of the work of instruction in schools. This report deals with hearing, 
teeth, playtime, and leisure. Some standard method of testing the hearing of children is desirable. Reports from other countries show that 12 per cent. to 20 per cent. of school children may be defective in their hearing. An examination of the teeth of 10,500 English and Scotch boys and girls of an average age of twelve years in poor law schools, workhouses, and reformatories showed only i4 per cent. of these children with teeth free from decay. The children in our public elementary schools are in a much more neglected state than the poor-law children. The committee thinks that daily cleansing of teeth should be enforced by parents and teachers, and that dentists employed by school authorities should make systematic examination of teeth.

Sir Lauder Brunton spoke on physical education, and showed that mind development was brain development. The teaching of hygiene might begin with the washing and dressing of dolls. He urged the medical inspection of schools, and brought to the notice of the section the National League of Physical Education and Improvement. His lecture was supported by a most welcome and generous distribution of pamphlets sent by that league, and his display of lantern-slides in the adjacent room when the botanists adjourned for lunch allowed of the presentation of evidence to a section which does not always find it easy to get at the facts which underlie opinions.

Dr. Ethel Williams gave careful estimates of the time, cost, and usefulness of medical inspection. In Newcastle, with 45,000 children on the books, three officers could inspect each child thrice in its school life at a cost of about $2000 l$. per annum, equivalent to a farthing rate. For the whole country $200,000 l$. would give similar inspection of children, with supervision of epidemics and of school buildings. Prof. Sadler pointed to the crux of the difficulty in getting parents to act on medical officers reports, and Mr. Ernest Gray spoke of the attitude of suspicion in the working classes. Major Salmon spoke of the Swedish system of gymnastics as developed in Denmark. To keep the air clean for breathing exercises a damp felt or sacking is passed over the floors before every lesson.

Mr. A. Burrell said that freedom to move in one's clothes and a sense of cleanliness were the bases of true hygiene. The rightly dressed, clean child, and the well ventilated class-room were the best lessons. Organised games had been approved, but playing centres had not yet been provided. A medico-ethical training was necessary for the teacher who was to stand hour by hour before weal sight, incipient deafness, and malnutrition. There should be a standard of health in training colleges analogous to that demanded by the Army and Navy.

Mrs. J. R. Macdonald showed how all schemes for the education of wage-earners of school age were bound up with social and economic questions. She urged a better enforcement of the Employment of Children Act, x903. Mr. Hugh O. Meredith described the Workers' Educational Association--an effort to organise the higher education of working men by means of collegiate life in local guilds associated with the University Extension movement. Mr. Arnold S. Rowntree explained how similar ends were achieved by the adult schools meeting on Sunday mornings.

The discussion in Section I on the physiological value of rest might almost have been called a joint meeting, considering its interest for those attending Section L. Dr. Acland found that sleep was necessary for the growth of the brain and nervous system, and that many schools had not secured sufficient sleep either for younger boys or for those older boys who needed it. Mental and bodily health cannot be severed, and muscular exertion is not a remedy for brain fatigue. Dr. Bevan Lewis correlated brain-fag with muscular fatigue. The minimum of sleep for growing children was not defined, but no one advocated less than nine hours. Laboratory investigation into the general laws of fatigue is needed in the opinion of Dr. W. H. R. Rivers. Dr. Macdougall suggested that early morning sunlight should be shut out of a child's room.

Sir Philip Magnus presented the report upon the course of Experimental, Observational, and Practical Studies most Suitable for Elementary Schools. The committee asks that

No. I924, voL. 74] active and constructive work on the part of children should be largely substituted for ordinary class-teaching. To make this possible, smaller classes, trained teachers, and sympathetic inspectors are necessary. Supplementary reports of subcommittees were presented by Prof. R. A. Gregory on arithmetic and mensuration, by Mr. R. H. Adie on naturestudy, and by Mr. George Fletcher on domestic work. There was an eager and universal request for copies of the full text of these reports, and the printed supply proved very unequal to the demand. The committee of the section proposed to arrange for further reprints. Prof. Green said that primary teachers needed training to use the freedom now given them, and needed also the opportunity of a higher professional course at the universities for those desirous of promotion. Mr. Cyril Jackson admitted the difficulties of large classes, Mr. T. P. Sykes emphasised the need for freedom to experiment, and Dr. Traill the importance of training teachers before trying to rush reforms through the schools.

In the discussion on School Training for the Home Duties of Women, Prof. A. Smithells said that at present home training reveals the methods of superstition, ignorance, prejudice, and folly. Nor does a formal course on the oxides of nitrogen and chlorides of phosphorus always produce a scientific attitude of mind in a household where ovens will not heat and meat will not keep. A schoolmistress with a scientific degree may fail to understand the hot-water system, the gas meter, or the filter. There is a more excellent way, and it is possible to develop a science of the household free from pedantry and free from empiricism in that vast undeveloped intellectual region connected with the domestic work of women. The discussion was continued by Prof. Armstrong, Prof. Millicent Mackenzie, and others.

The morning of Monday, August 6, was reserved for those public- and secondary-school questions relating to the Balance of Subjects in the Curriculum, the perennial interest in which has lately been revived by "Kappa" and by the "Upton Letters." Papers contributed by the Hon. and Rev. E. Lyttelton and by Mr. A. C. Benson were read in the absence of the authors. The possible omission of Latin in the preparatory school seems to have come within the range of discussion; at any rate, precedence for French seems agreed upon. Mr. T. E. Page proposed a committee to draw up a scheme of general study, to indicate the method and purpose of teaching the various subjects, and to show at what stage specialisation should be allowed. Mr. G. Gidley Robinson spoke of the preparatory-school master as not a free agent, scholarships being the root of the mischief. Mr. Arthur Rowntree assumed that training for power of work and service should be the prime object of education, and asked for an unburdening of the curriculum to allow of individuality in leisure hours.

Scientific Method in the Study of School Teaching was described by Prof. J. J. Findlay. Progress has been hindered by those earlier advocates of training who treated education merely as applied logic and ethics, but progress may be expected from experimental psychology and genetic psychology or child study. The popular interest in education leads to the ready adoption of opinions rather than the encouragement of prolonged investigations; but results in methods of school teaching can only be secured by observation of children. Educational experiments require the cooperation of several teachers for several years without external interference. Reforms have recently been introduced by external pressure, and only very inadequately tested by scientific experiments within the schools. Teachers should work in their schools as in a laboratory; but scientific habits are not easily acquired, and men trained in one branch of science do not readily transfer their scientific habits to the regions of prejudice and tradition. The demonstration schools at Manchester propose to investigate a few special topics, such as the elementary teaching of modern languages, practical mathematics, the association of parents with school life, and a school camp Prof. Findlay applied his experimental methods for mor than five years in Cardiff to discover the Processes involved in the Acquirement of a Foreign Language. The procese is fundamentally one of acquiring habits of automatic reaction in the association of foreign symbols with ideas. 
The native speech centre is a special hindrance, and the translation habit, although the path of least discomfort, is really a bar to progress. The rate of progress depends upon the intensity of the learner's absorption during the early stage. Inquiry into cases of aphasia among bilingual people may be expected to throw some light upon the nature of brain centres for foreign speech. The attempt to establish two foreign languages at the same time should not be made; each tends to inhibit the other. Latin, however, taken on a translation method does not appreciably interfere. Progress is hindered by the incapacity of some scholars to perceive new sounds.

The discussion on the Examination and Inspection of Schools was started by Prof. Armstrong, who asserted the need for freedom to develop individuality. The ideal system would be for the schools to examine themselves with the aid occasionally of competent assessors. $\mathrm{Mr}$. W. M. Heller spoke on the constructive work of an in spector of schools. The transition from payment by results to inspection was accompanied for some years by a diminution in the proficiency of pupils. An inspector should possess successful teaching experience in both primary and secondary schools, if possible with the wider outlook of headmaster. It takes time to know a large number of schools and teachers, and first impressions are sometimes wrong; hence an inspector should be left for several years in the same district. An inspector has a magnificent field for scientific research; he can watch, foster, and institute educational experiments of all kinds. The Rev. E. C Owen doubted whether the inferior teacher well inspected was an improvement on the good teacher uninspected. Training would never eliminate mediocrity. If practical experience in teaching were made a sine qua nún for administrative posts, this would attract good men to educational work.

A joint meeting was held with Sections A and G to discuss the Teaching of Mechanics by Experiment. Mr. C. E. Ashford spoke of the results obtained at Dartmouth by the cooperation of schoolmaster and engineer, and the use of real machinery instead of scientific toys. The science master who plays with laboratory toys is apt to be too academic, and the technical schools are too rule-of-thumb, lacking the rigorous mathematician and trained educationist; but the finest of laboratory toys were the delightful trolleys and vibrating springs shown by the lecturer and used by his pupils for measuring velocity, acceleration, and momentum.

Those who attended Section L greatly enjoyed Prof. Sadler's chairmanship, " serious and sunny." His summing up at the close of each day's discussion pointed through primitive chaos to the spirit of search, the growing desire for educational unity, and the fading away of narrow aims.

HUGH RichaRDSON.

\section{INTERNATIONAL TESTING CONGRESS.}

IN NATURE of September 6 (p. 47I) brief reference was made to the opening of the International Testing Congress at Brussels on September 3. The work of the sections began on September 4, and was continued on September 5 and 6 . The amount of work to be dealt with was so considerable that three sections were formed, A dealing with metals, $\mathrm{B}$ with building stone and cement, and $C$ with other materials. Altogether there were twentyseven reports of committees and forty-five original papers, the greater portion of which were submitted to the section on metals. Mr. J. Magery (Namur) presided over this section, and he was supported by honorary presidents representing the various nationalities present, and including Messrs. Wedding (Berlin), Brough (London), Saladin (France), Hackstroh (Holland), Chernoff (Russia), Brinell (Sweden), Popper (Austria), and Tonello (Spain). The following are brief notes on the various reports presented:Mr. A. Rieppel (Nuremberg) reported on the introduction of standard specifications in various countries; $\mathrm{Mr}$. W. Ast (Vienna) reported on methods for inspecting and testing in order to ensure uniformity in iron and steel ; Mr. R. Krohn (Danzig) reported that it was not feasible to establish standard welding tests. Prof. E. Heyn (Berlin), reporting on the value of etching malleable iron for the investigation of structure, showed that examination by the unaided eye gave valuable information as to the character of quenched high-carbon steel. Prof. N. Belelubsky (St. Petersburg) reported on the unification of methods of testing, and submitted a series of proposals. Prof. H. M. Howe and Mr. A. Sauveur submitted proposals for the uniform nomenclature of iron and steel. Dr. R. Moldenke (New York) reported on the establishment of standard methods of testing cast-iron and finished castings. He noted that the American and German specifications differ but slightly, and could easily be made identical.

Mr. E. Sauvage (Paris) submitted a report on impact tests on notched bars, and there was an animated discussion as to the value of this method of testing, opinions being equally divided as to the desirability or not of recommending it in specifications. The Brinell hardness test, which was reported on by Mr. J. A. Brinell and Mr. G. Dillner (Stockholm), was also keenly discussed, the general opinion being that, with the view of placing information on record, tensile tests of metals should, when possible, be supplemented by tests by the Brinell method. Mr. W. Ast (Vienna) submitted a report on international researches in the macroscopic examination of iron. The etching test is recommended for preliminary examination. Lastly, Mr. F. Osmond and Mr. G. Cartaud (Paris) submitted an interesting report on the progress of metallography since the Budapest congress of $190 \pi$.

The second section, dealing with cements, was under the presidency of $\mathrm{Mr}$. Levie (Charleroi). The subjects discussed included the determination of the adhesive force of hydraulic cement, the determination of the weight of a litre of cement, and the behaviour of cement in sea-water. It was decided to appoint a committee to inquire into reinforced concrete.

The third section, under the presidency of $\mathrm{Mr}$. E. Roussel (Malines), devoted attention to tests of paints, linseed oil, wood, bitumen, asphalt, and india-rubber. The congress concluded with a lecture by Prof. H. Le Chatelier (Paris) on the practical applications of metallography. An interesting feature of the congress was a small laboratory installed to illustrate modern methods of testing, under the direction of Prof. Le Chatelier, Mr. Guillet (Paris), and Prince Gagarine (St. Petersburg). It was decided that the next congress should be held in 1909 in Copenhagen under the presidency of Mr. A. Foss, president of the Society of Danish Engineers.

\section{THE ANTI-TUBERCULOSIS CAMPAIGN.}

THE Hague, preparing to receive the great Peace Congress of 1907 , which is to discuss questions of peace and disarmament, recently entertained delegates from the chief European and American States to the fifth International Conference on Tuberculosis. At this conference questions of increased armaments were discussed, with the view of waging a more effective war against this great evil. The great interest taken all over the world in the proceedings of the conference testifies to the awakening of mankind to the necessity of making further and greater efforts in order to reduce the ravages of tubercular infection to a minimum.

At the present time the campaign against tuberculosis is being carried on with greater energy than at any previous period in medical history. Since Koch's discovery of the tubercle bacillus in 1882 , and the publication of his exhaustive researches arising therefrom, it has been known to medical men that tuberculosis is as much a preventable disease as plague or cholera. Nevertheless, the public in England have remained until very recently apathetic and apparently indifferent to the fact that untold misery and sixty thousand actual deaths occur annually from a disease which can and ought to be eradicated. At last we are waking from our lethargy. This change has been gradually induced by the insistent pressure of medical opinion, aided largely by the King's active sympathy and interest. More lately Prof. Wright's great work on "opsonins" has given fresh hope and energy to many who were becoming jaded in an apparently hopeless conflict.

NO. I 924, voL. 74] 